Incheon International Airport (ICN) is one of the hub airports in East Asia. Airport operations at ICN have been growing more than $5 \%$ per year in the past five years. According to the current airport expansion plan, a new passenger terminal will be added and the current cargo ramp will be expanded in 2018. This expansion project will bring 77 new stands without adding a new runway to the airport. Due to such continuous growth in airport operations and future expansion of the ramps, it will be highly likely that airport surface traffic will experience more congestion, and therefore, suffer from efficiency degradation. There is a growing awareness in aviation research community of need for strategic and tactical surface scheduling capabilities for efficient airport surface operations. Specific to ICN airport operations, a need for A-CDM (Airport - Collaborative Decision Making) or S-CDM(Surface - Collaborative Decision Making), and controller decision support tools for efficient air traffic management has arisen since several years ago. In the United States, there has been independent research efforts made by academia, industry, and government research organizations to enhance efficiency and predictability of surface operations at busy airports. Among these research activities, the Spot and Runway Departure Advisor (SARDA) developed and tested by National Aeronautics and Space Administration (NASA) is a decision support tool to provide tactical advisories to the controllers for efficient surface operations. The effectiveness of SARDA concept, was successfully verified through the human-in-the-loop (HITL) simulations for both spot release and runway operations advisories for ATC Tower controllers of Dallas/Fort Worth International Airport (DFW) in 2010 and 2012, and gate pushback advisories for the ramp controller of Charlotte/Douglas International Airport (CLT) in 2014. The SARDA concept for tactical surface scheduling is further enhanced and is being integrated into NASA's Airspace Technology Demonstration - 2 (ATD-2) project for technology demonstration of Integrated Arrival/Departure/Surface (ADS) operations at CLT. This study is a part of the international research collaboration between KAIA (Korea Agency for Infrastructure Technology Advancement)/KARI (Korea Aerospace Research Institute) and NASA, which is being conducted to validate the effectiveness of SARDA concept as a controller decision support tool for departure and surface management of ICN. This paper presents the preliminary results of the collaboration effort. It includes investigation of the operational environment of ICN, data analysis for identification of the operational characteristics of the airport, construction and verification of airport simulation model using Surface Operations Simulator and Scheduler (SOSS), NASA's fast-time simulation tool. 


\title{
Operational Characteristics Identification and Simulation Model Validation for Incheon International Airport
}

\author{
Yeonju Eun ${ }^{1}$, Daekeun Jeon ${ }^{2}$ \\ Korea Aerospace Research Institute, Daejeon, South Korea \\ Hanbong Lee ${ }^{3}$ \\ University of California, Santa Cruz, NASA Ames Research Center, Moffett Field, CA, 94035, U.S.A \\ Zhifan Zhu ${ }^{4}$ \\ Stinger Ghaffarian Technologies Inc., NASA Ames Research Center, Moffett Field, CA, 94035, U.S.A \\ Yoon C. Jung 5 \\ NASA Ames Research Center, Moffett Field, CA, 94035, U.S.A \\ and
}

Myeongsook Jeong ${ }^{6}$, Hyounkyong $\mathrm{Kim}^{7}$, Eunmi $\mathrm{Oh}^{8}$, Sungkwon Hong ${ }^{9}$, and Junwon Lee ${ }^{10}$

Korea Aerospace Research Institute, Daejeon, South Korea

\begin{abstract}
Integrated surface and departure management based on Collaborative Decision Making (CDM) concepts is being studied to improve the operational efficiency and cope with the continuous growth of traffic demands at Incheon International Airport (ICN), South Korea. This study is a part of the research collaboration between Korea Agency for Infrastructure Technology Advancement (KAIA) / Korea Aerospace Research Institute (KARI) and National Aeronautics and Space Administration (NASA). A sequence of research activities are planned to study new concepts of airport operations and advanced decision support tools. As an initial accomplishment toward this research goal, this paper presents the results of the current day operations analysis to identify its traffic characteristics. A fast-time simulation model is developed based on the data analysis, and model validation is performed using heavy traffic scenarios. The validation results indicate that the developed simulation model corresponds well with current airport surface operations of ICN, which implies the model can be useful for the next steps of research, including the development of scheduling concepts and algorithms.
\end{abstract}

\section{Introduction}

TCHEON International Airport (ICN), situated 26 miles west from Seoul, South Korea, is one of the hub airports in East Asia. Airport operations at ICN have been growing more than $5 \%$ per year in the past five years.

${ }^{1,7}$ Senior Researcher, CNS/ATM Team, Korea Aerospace Research Institute, 169-84 Gwahak-ro, Yuseong-gu, Daejeon 305-806, South Korea.

${ }^{2}$ Principal Researcher, CNS/ATM Team, Korea Aerospace Research Institute, 169-84 Gwahak-ro, Yuseong-gu, Daejeon 305-806, South Korea.

${ }^{3}$ Associate Research Scientist, UARC, Mail Stop 210-8, Moffett Field, CA 94035, U.S.A.

${ }^{4}$ Senior Software Engineer, Stinger Ghaffarian Technologies, Mail stop 210-8 Bldg N210, P O Box 1, Moffett Field, CA 94035, U.S.A.

${ }^{5}$ Aerospace Engineer, Aerospace High-Density Operations Research Branch, Mail Stop 210-6, NASA Ames Research Center, Moffett Field, CA 94035, U.S.A, AIAA Senior Member.

6, 8-10 Researcher, CNS/ATM Team, Korea Aerospace Research Institute, 169-84 Gwahak-ro, Yuseong-gu, Daejeon 305-806, South Korea. 
According to the current airport expansion plan, a new passenger terminal will be added and the current cargo ramp will be expanded in 2018. This expansion project will bring 77 new stands or gates without adding a new runway to the airport. Due to such continuous growth in airport operations and future expansion of the ramps, it is highly likely that airport surface traffic will experience more congestion, and therefore, suffer from efficiency degradation.

There is a growing awareness in the aviation research community of a need for strategic and tactical surface scheduling capabilities for efficient airport surface operations. Specific to ICN airport operations, a need for A-CDM (Airport - Collaborative Decision Making ${ }^{6}$ ) or S-CDM (Surface - Collaborative Decision Making ${ }^{7}$ ), and controller decision support tools for efficient air traffic management has arisen within the past few years. In the United States, there have been independent research efforts made by academia, industry, and government research organizations to enhance efficiency and predictability of surface operations at busy airports. ${ }^{8-10}$ Among these research activities, the Spot and Runway Departure Advisor (SARDA) developed and tested by National Aeronautics and Space Administration (NASA) is a decision support tool to provide tactical advisories to the controllers for efficient surface operations. The effectiveness of the SARDA concept was successfully verified through the human-in-theloop (HITL) simulations. SARDA's spot release and runway operations advisories for Air Traffic Control Tower (ATCT) controllers were evaluated for Dallas/Fort Worth International Airport (DFW) in 2010 and 2012 $2^{2}$, and gate pushback advisories for the ramp controllers of Charlotte Douglas International Airport (CLT) were tested in 2014. ${ }^{3}$ The SARDA concept for tactical surface scheduling is being further enhanced and integrated into NASA's Airspace Technology Demonstration - 2 (ATD-2) project for Integrated Arrival/Departure/Surface (IADS) operations and will be demonstrated at CLT. ${ }^{11}$

This study is a part of the international research collaboration between KAIA (Korea Agency for Infrastructure Technology Advancement) / KARI (Korea Aerospace Research Institute) and NASA to validate the effectiveness of the SARDA concept as a controller decision support tool for departure and surface management of ICN.

This paper is organized as follows. Section II describes the general information about ICN, and provides a summary of the operational environment of the airport. In Sections III and IV, flight data acquisition and analysis results are described for the identification of the operational characteristics of the airport, respectively. In Section V, the development of an airport simulation model using the Surface Operations Simulator and Scheduler (SOSS) ${ }^{5}$, NASA's fast-time simulation tool, is presented. In Section VI, the simulation model validation process and results are described. Lastly, Section VII provides concluding remarks and briefly discusses future research plans.

\section{General Information about ICN}

The airport configuration of ICN is shown in Fig. 1. There are three parallel runways at ICN. Runway 33R/15L and $33 \mathrm{~L} / 15 \mathrm{R}$ are two parallel runways with the distance of $400 \mathrm{~m}$ between them. Runway $33 \mathrm{R} / 15 \mathrm{~L}$ is used primarily for arrivals and 33L/15R is primarily for departures. Runway 34/16 is used for both departures and arrivals, and the usage is changed several times a day depending on the departure and arrival traffic demands. All cargo flights take off and land using the runways $33 \mathrm{R} / 15 \mathrm{~L}$ and $33 \mathrm{~L} / 15 \mathrm{R}$, exclusively, whereas the passenger flights can use all three runways. Takeoff and landing on Runway 34/16 is not allowed from 21:00 to 09:00 the next day, except for emergency aircraft, or severe conditions regarding weather, ground, and traffic volume.

The control authority and towers for the movement areas (i.e., taxiways and runway) and ramp areas (both main and cargo ramp) of ICN are completely separated. The startup and pushback clearances and taxi guidance services for aircraft in the ramp areas are provided by the airport authority (i.e., Incheon International Airport Corporation).

ICN is located in the north-west side of Incheon Flight Information Region (FIR), which is bordered by Shanghai FIR of China on its west side, Fukuoka FIR of Japan on its south-east side and Pyongyang FIR of North Korea on its north

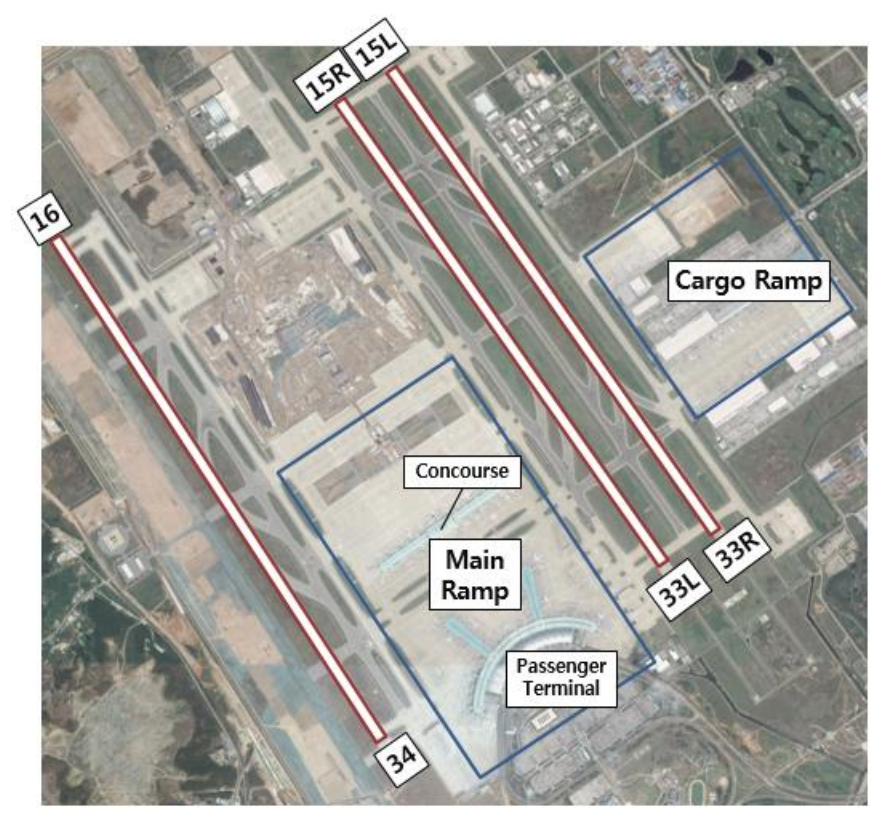

Figure 1. Airport configuration of ICN 
side, as shown in Fig. 2. Available airspace to the north of the airport is very limited due to the flight prohibited areas on the border of North Korea. Inbound and out-bound traffic from/to Pyongyang FIR are prohibited. The distance to the border of Shanghai FIR is approximately $120 \mathrm{~nm}$, therefore, the Traffic Management Initiatives (TMIs) from Shanghai FIR are major constraints for scheduling of the departure flights entering Shanghai FIR from ICN. In the Seoul Terminal Maneuvering Area (TMA), in which ICN is located, there is another major Korean airport, Gimpo International Airport (GMP). The route $\mathrm{Y} 71 / \mathrm{Y} 72$ in Fig. 2, which is shared between ICN and GMP for the south-bound traffic to Jeju TMA, is the busiest air route in Korea with 14 departures per hour on average in $2014^{16}$, and also used by the flights to South-Asia and Oceania (i.e., a region centered on the islands of the tropical Pacific Ocean) from ICN.

The total number of departure and arrival flights of ICN was 290,043 in 2014. Since the beginning of airport operations in March 2001, the traffic has continuously increased except for the years of 2007-2008 and 2008-2009 due to the global economic crisis in 2008. Notably, the annual increase rate has been higher than $5 \%$ for the last five years as shown in Fig. 3. If the increase rate of 5\% per year continues, the traffic volume is expected to be doubled by 2030. ICN has an expansion plan of a total of 5 phases, and currently, the phase 3 expansion is underway. The phase 3 expansion plan includes construction of a new passenger terminal and cargo ramp expansion, which will result in 56 new stands for passenger flights (currently 109) and 21 new stands for cargo flights (currently 36). These new stands are scheduled to operate starting in 2018 (Incheon International Airport Corporation).

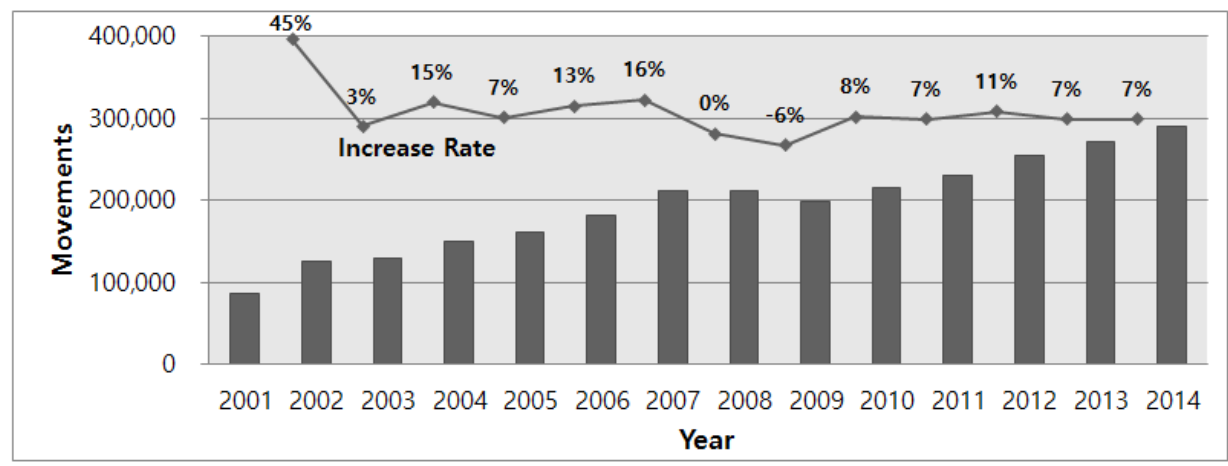

Figure 3. Traffic volume of ICN (Data source: Korea Civil Aviation Development Association)

\section{ICN Flight Data Acquisition and Pre-processing}

In order to verify the operational considerations and identify the characteristics of ICN operations, data analysis has been conducted. The data were collected for the departure and arrival flights during April 2015, which included Airport Surface Detection Equipment (ASDE) track data, flight plans from Automatic Radar Terminal System Flight Data Processor (ARTS-FDP), and operational data from Flight Operations Information System (FOIS) ${ }^{12}$ and Flight Information Management System (FIMS) ${ }^{13}$. The FOIS and FIMS are dedicated systems used for air traffic management in Korea. The FOIS is used for arrival and departure time management for the flights through all the airports in Korea. The FIMS is an information management system for the departure and arrival flights through ICN. It provides the controllers with flight information such as the given input data from FOIS and the other available data for ICN operations.

The data items of ASDE track data, ARTS-FDP flight plans, FOIS, and FIMS outputs are described in Table 1. Flight data from each data source include the specific data items, such as Callsigns and tail numbers, which are used for identification of each individual flight. Using those data items, the flight data were reconstructed by matching the 
flight plans and FOIS/FIMS data with the valid ASDE tracks. Then, the data analysis, simulation model development and validation described on Section IV-VI of this paper were conducted based on this reconstructed flight data.

Table 1. Flight data sources and data items

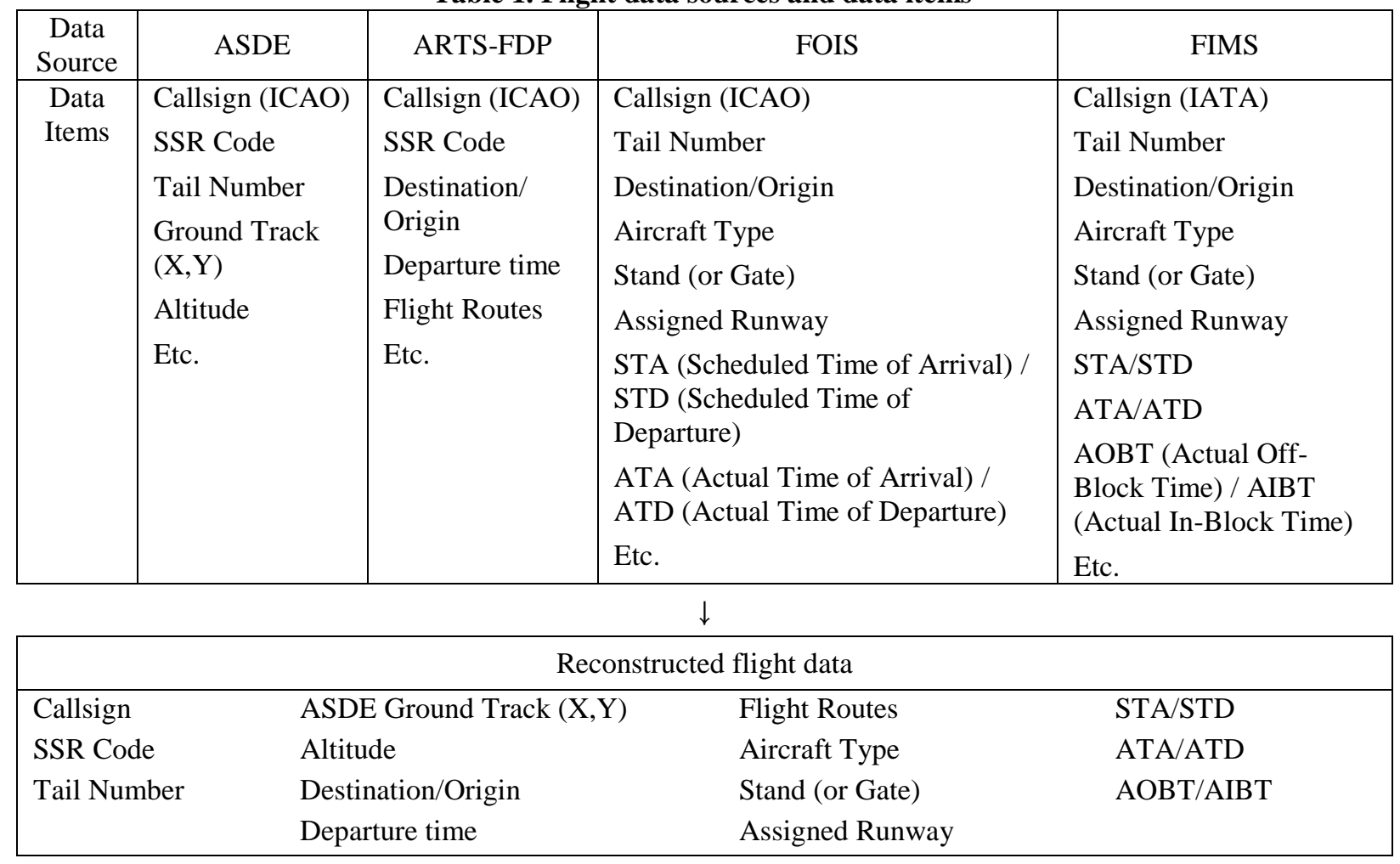

\section{Data Analysis Results}

Data analysis of the flight data of April 2015 has been conducted for identification of characteristics of ICN surface traffic.

\section{A. Surface Traffic Heat Map}

First of all, airport surface heat maps were generated using the summations of stop durations ${ }^{1}$ during the taxi-out phase of flight. These heat maps present direct indications of the locations and severities of the stops. In these heat maps, the 'stop' is defined as a moment when the speed of aircraft is less than $1 \mathrm{~m} / \mathrm{s}$ during 'taxi-out'. The valid track data for 'taxi-out' are the track data from the moment when aircraft have moved faster than $3 \mathrm{~m} / \mathrm{s}$ of speed for the first time, after pushback from the stand or gate, and to the moment when aircraft entered into the line-up area for takeoff. The XY positions in the ASDE ground tracks are reliable measurements, but too noisy to calculate the speeds. Therefore, the ASDE ground tracks were smoothed using the Rauch-Tung-Striebel (RTS) smoother, and then stops were identified using the speeds, which were calculated based on the smoothed tracks.

Figures 4 and 5 are the heat maps for north and south flow departures, respectively. The colors represent the intensity of cumulative seconds of stop durations, and the colors change in log scale in both figures. The tracks used in these figures are the valid track data of all departures from ICN in April 2015. The numbers of tracks used for constructing those heat maps are 7,252 for north flow and 5,180 for south flow. These heat maps show that some stops occurred on the taxiways in the movement area rather than in the ramps, and that these stops also illustrate the departure queues of ICN. 


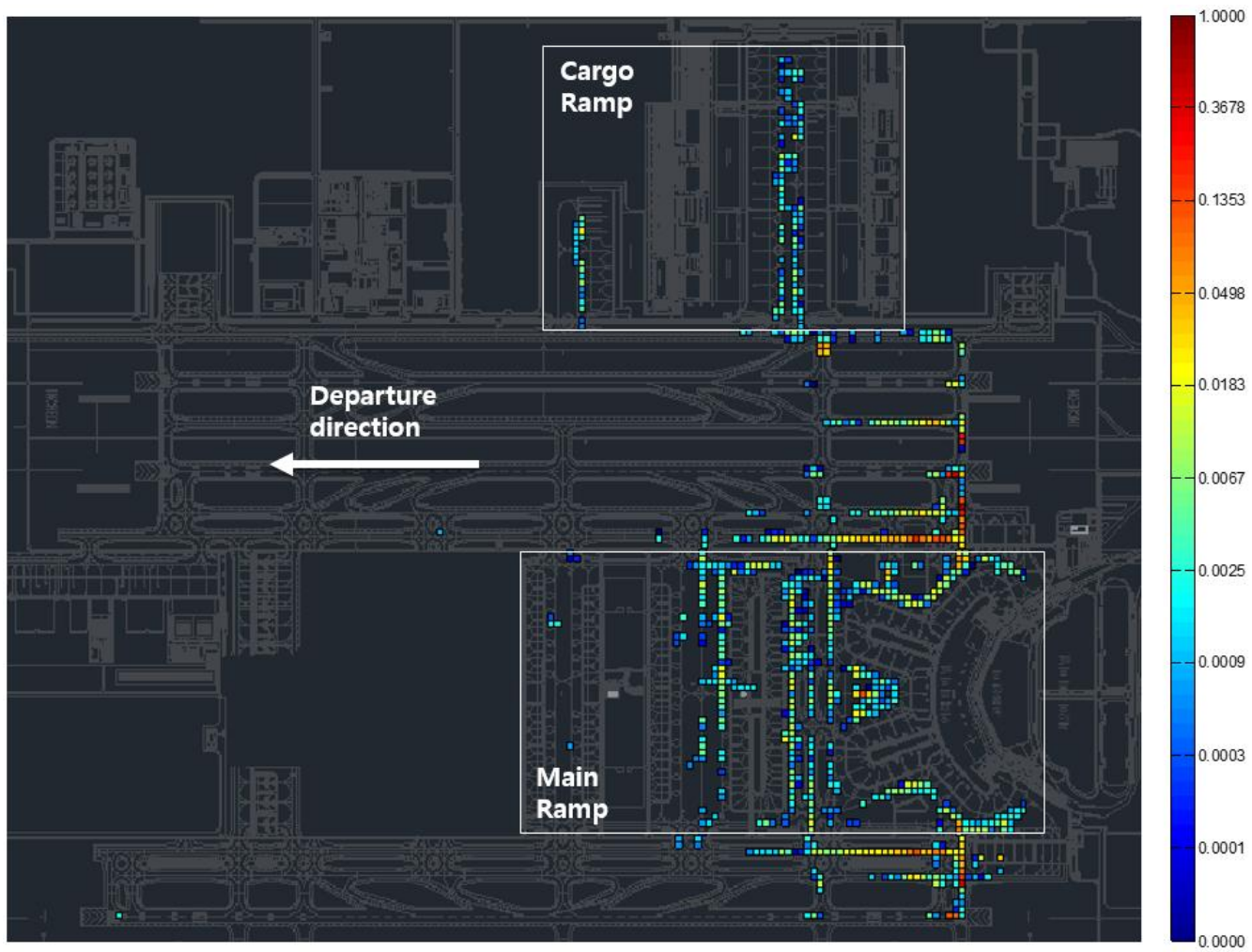

Figure 4. ICN Surface heat map for the stops during the taxi-out phase of north flow departures (April 2015)

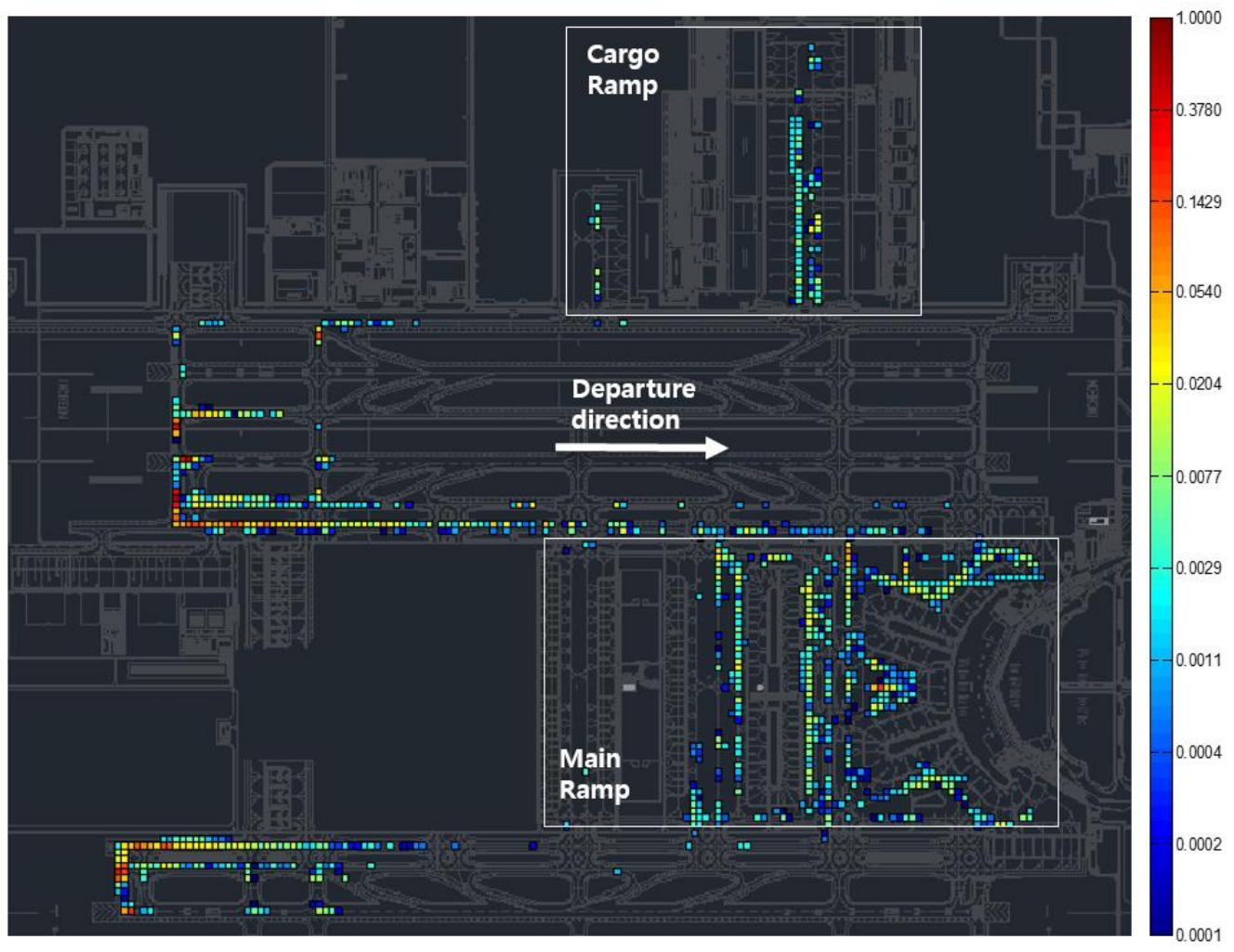

Figure 5. ICN Surface heat map for the stops during the taxi-out phase of south flow departures (April 2015)

American Institute of Aeronautics and Astronautics 
This heat map analysis can help us better understand the characteristics of departure queues. For example, Fig. 6 shows the heat map using stop durations of the flights departed during the time period, 22:30 - 23:00 on April 2nd, 2015. In this figure, Taxi Route - A and C are the standard taxi routes for the departures from Main Ramp and Cargo Ramp, respectively. Taxi Route $-\mathrm{B}$ is a non-standard taxi route, which is utilized in some abnormal conditions, such as traffic congestions or ground

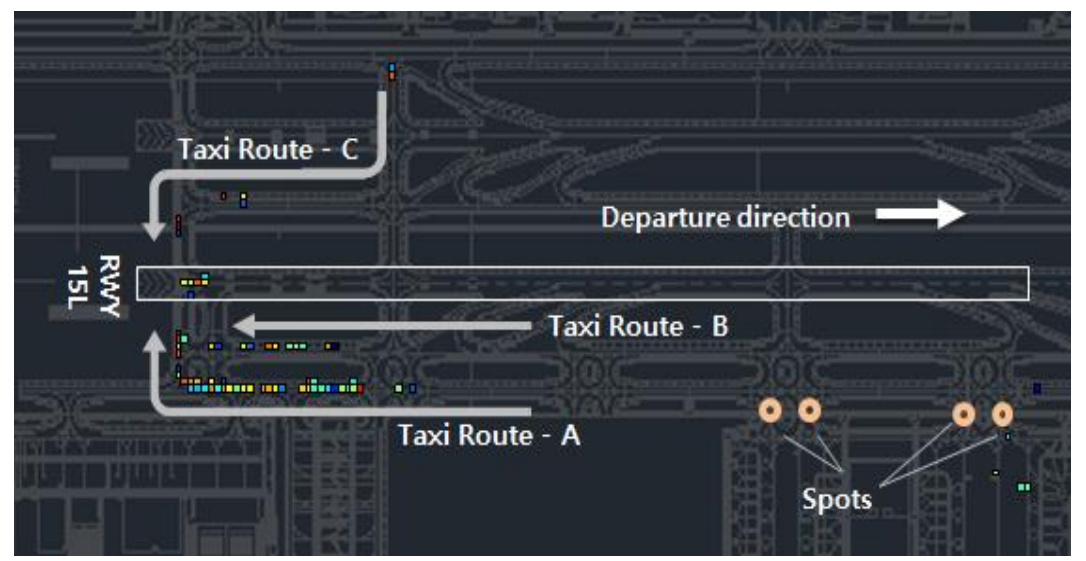

Figure 6. Multiple queue lanes for departures toward Runway 15L

holdings. In this example, a long departure queue was observed on Taxi Route - A that started almost from the spot locations during 22:15-22:30, and Taxi Route - B started to be utilized after 22:30. Based on these observations, the multiple queue lanes for departure from Main Ramp to Runway 15L can be considered for the application of runway scheduling algorithms, such as SARDA.

\section{B. Runway Configuration and Assignment Strategy}

As noted in Section II, Runway $33 \mathrm{R} / 15 \mathrm{~L}$ is used primarily for arrivals and $33 \mathrm{~L} / 15 \mathrm{R}$ is primarily for departures, whereas Runway 34/16 is used for both departures and arrivals. It is also known that the usage of Runway 34/16 changes several times in a day depending on the departure and arrival traffic demand. Figure 7 shows the variation of Airport Departure Rate (ADR) during a day, based on the flight data in April 2015. The departure rate is defined as the number of departures (or wheels-off) in a 15-minute time interval. The time period with zero departure rates for Runway $34 / 16$ in Fig. 7 is the time when Runway $34 / 16$ was used for arrivals only or closed. Fig. 7 also shows that the departure rate of Runway 34/16 was higher than Runway 33/15 during the time when Runway 34/16 was used for departures.

In order to analyze the cause of the imbalanced departure rates on the runways, runway assignment strategies were investigated based on the flight data. Departure route directions of the flights and fleet mixture in terms of wake turbulence categories were checked using the actual flight data (i.e. the reconstructed flight data) of April 2015. Figure 8 shows the assigned runway mixture ratio of departure flights for each departure route direction during the time

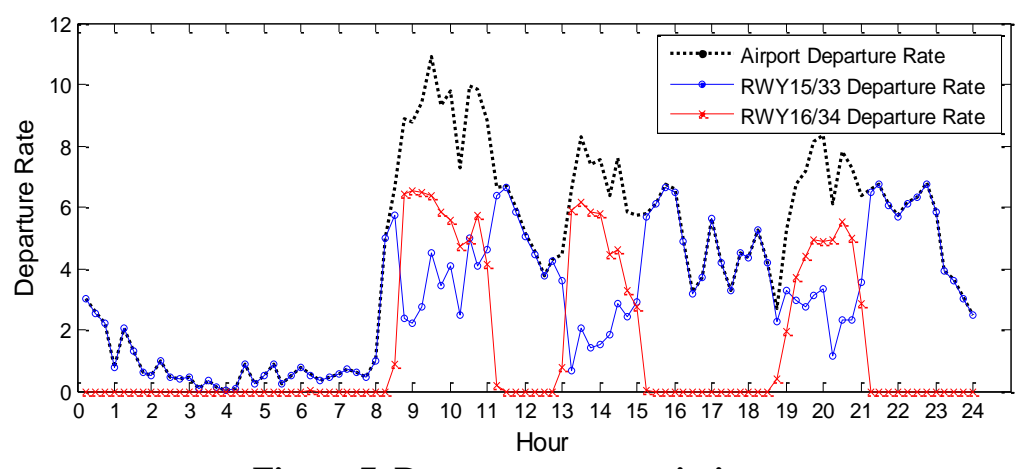

Figure 7. Departure rate variation

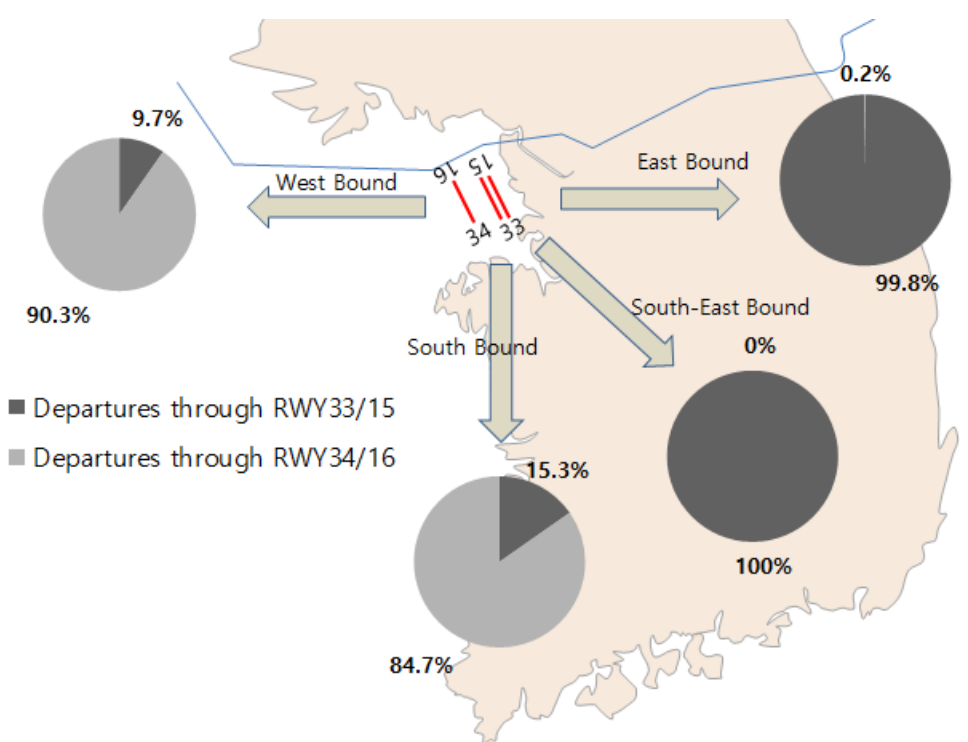

Figure 8. Assigned runway mixture ratio for each departure route direction

6

American Institute of Aeronautics and Astronautics 
period when Runway 34/16 was used for departures, and it simply shows that the runway assignment of departure flights mainly depends on the departure route direction. The $0.2 \%$ of Runway $34 / 16$ assignment ratio to the departures bound for the east direction is an exceptional case with a single flight count. Except for that case, all departures bound for east or south-east direction (ES) were assigned to Runway 33/15. Meanwhile, the departures bound for west or south direction (WS) were assigned mainly to Runway 34/16, and some of them were assigned to Runway 33/15. All cargo departures were assigned to Runway 33/15 regardless of their departure route direction. However, not all the departures through Runway 33/15 and bound for WS were cargo flights. Only $21.4 \%$ of the WS-bound departures through Runway 33/15 were freighters. This result indicates that some of the passenger flights bound for WS were assigned to Runway 33/15 during the time period when both Runway 34/15 and 33L/15R were used for departures.

Figure 9 presents the cumulative number of departures bound for WS (at the top) and ES (at the bottom) in April 2015. The grey-colored sections on the background of the graphs represent the time periods when both Runway 34/16 and 33L/15R were typically used for departures during April 2015. It is recognizable that the demands of WSbound flights is much higher than ES-bound flight over the whole period, and that the peak hours of total demand coincide with the peaks of the WS-bound flights. Runway 34/16 was used for departures during these peak hours to deal with the high traffic volumes of the WS-bound flights, and even Runway 33L/15R was assigned to some WSbound flights, as shown in Fig. 8 .
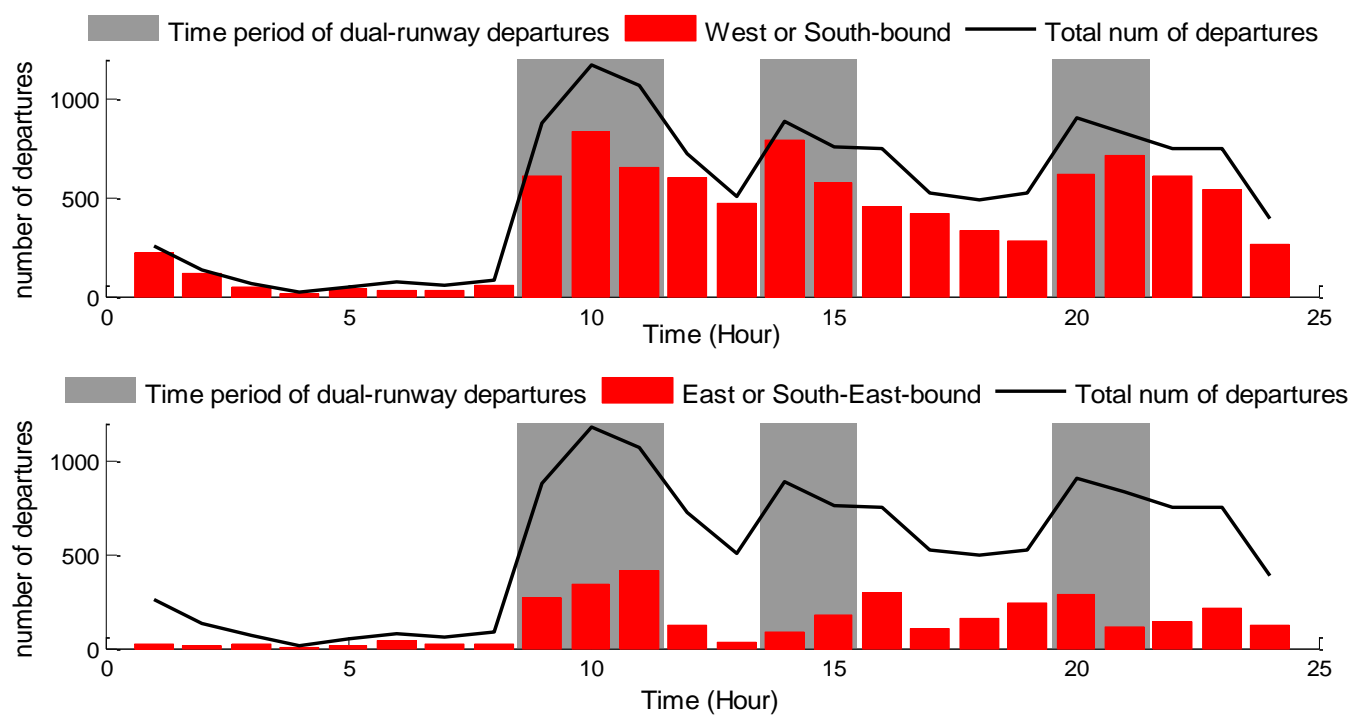

Figure 9. Cumulative number of departures bound for WS/ES

The fleet mixture ratio in terms of wake turbulence category at each runway is presented in Tables 2 and 3 . The tables show the assigned runway ratio in each wake turbulence category. These ratios were calculated using the flight data of departures and arrivals during the time period when Runway 34/16 was used for departures and arrivals exclusively. The wake turbulence category mixture ratio of each runway in Table 2 does not show any significant distinction, suggesting a similar tendency with the total mixture ratio, while the runway assignment ratio of super heavy class jets (e.g., A380) in Table 3 has somewhat distinct characteristics.

Table 2. Fleet mixture ratio in terms of a wake turbulence category

\begin{tabular}{|c|c|cccc|c|}
\hline \multicolumn{2}{|c|}{} & Small & Medium & Heavy & Super Heavy & Sum \\
\hline \multirow{3}{*}{ Departure } & Total & $0 \%$ & $47.0 \%$ & $51.1 \%$ & $1.9 \%$ & $100 \%$ \\
\cline { 2 - 7 } & Runway 33/15 & $0 \%$ & $48.3 \%$ & $49.4 \%$ & $2.3 \%$ & $100 \%$ \\
\cline { 2 - 7 } Arrival & Runway 34/16 & $0 \%$ & $44.4 \%$ & $54.4 \%$ & $1.2 \%$ & $100 \%$ \\
\cline { 2 - 7 } & Runway 33/15 & $0 \%$ & $46.4 \%$ & $52.1 \%$ & $1.5 \%$ & $100 \%$ \\
\cline { 2 - 7 } & Runway 34/16 & $0 \%$ & $48.9 \%$ & $47.7 \%$ & $3.4 \%$ & $100 \%$ \\
\hline
\end{tabular}


Table 3. Assigned runway mixture ratio in each wake turbulence category

\begin{tabular}{|c|c|c|c|c|c|}
\hline \multirow{3}{*}{ Departure } & & Small & Medium & Heavy & Super Heavy \\
\hline & Runway 33/15 & $0 \%$ & $36.4 \%$ & $35.8 \%$ & $71.5 \%$ \\
& Runway 34/16 & $0 \%$ & $63.6 \%$ & $64.2 \%$ & $28.5 \%$ \\
\hline \multirow{3}{*}{ Arrival } & Sum & $0 \%$ & $100 \%$ & $100 \%$ & $100 \%$ \\
\hline & Runway 33/15 & $0 \%$ & $44.5 \%$ & $55.0 \%$ & $35.3 \%$ \\
& Runway 34/16 & $0 \%$ & $55.5 \%$ & $45.0 \%$ & $64.7 \%$ \\
\hline & Sum & $0 \%$ & $100 \%$ & $100 \%$ & $100 \%$ \\
\hline
\end{tabular}

The flight demand of super heavy jets bound for WS is lower than for ES, and the demand ratio is 0.32:0.78 (WS:ES). Based on this demand ratio, the runway assignment ratio of super heavy jet departures in Table 3 seems reasonable, but almost contrary in the case of super heavy jet arrivals. According to the data analysis results, all super heavy jet departures were assigned to the appropriate runways in accordance with the flight directions, whereas, for more than half of the cases, the super heavy jet arrivals from ES were assigned to Runway 34/16 instead of Runway 33R/15L during the time period when both runways were used for arrivals. The runway assignment dependency on flight directions is weaker for the arrivals than departures at ICN, and $36 \%$ of the arrivals from ES were assigned to Runway 34/16 instead of Runway 33R/15L during the time periods when both runways were used for arrivals. For the super heavy jets, 55\% of the super heavy jet arrivals from ES were assigned to Runway 34/16 during the same time periods. One possible explanation is that landing on Runway 33R/15L involves crossing the departure runway (Runway 33L/15R) for the passenger flights, which is preferred by neither the controllers nor the airlines for such a big aircraft. Movement of super heavy class aircraft is one of the high priority considerations even for controllers, and they tend to assign the aircraft to the most convenient runway for taxi-in.

\section{Airport and Departure Throughputs}

Lastly, the airport and departure throughput performance evaluation using departure rate saturation curves ${ }^{4}$ was conducted to identify the capacity limit for the runways and movement areas, and help quantify the traffic congestion level criteria for ICN. The airport-level combined departure and arrival throughput saturation curve is presented in Fig. 10, where the numbers of aircraft taxiing-out and taxiing-in are defined as the numbers of aircraft inside of the movement areas (after passing a spot and before wheels-off for a departure, after wheels-on and before passing a spot for an arrival) during the same 15-minutes intervals of the throughput. Since the departure rates of Runway 33/15 are affected by the rates of arrivals due to runway crossing, the combined departure and arrival rates were considered as the airport throughput. The curve shows that the total airport throughput starts saturation around twenty aircraft in the movement area. The two graphs in Fig. 11 are the departure throughput saturation curves for Runway 33/15 and 34/16, respectively. The curves indicate the departure throughput saturation at about ten departure flights in the movement area towards the departure runway.

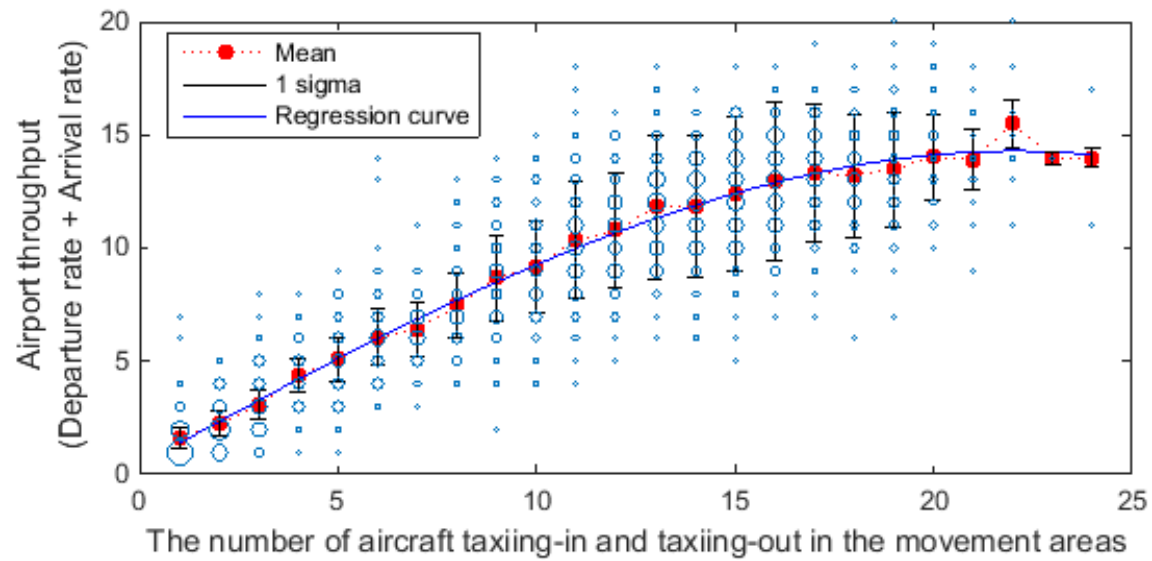

Figure 10. Airport throughput saturation curve 

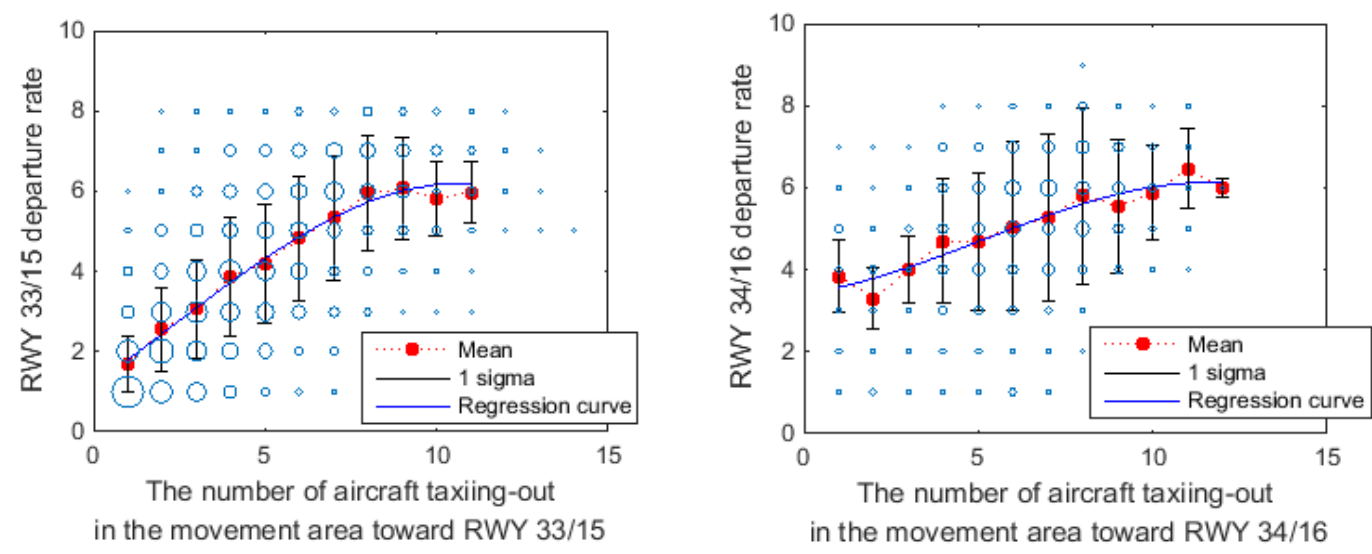

Figure 11. Departure throughput saturation curves for Runway 33/15 (left) and Runway34/16 (right)

\section{Fast-time Simulation Model}

SOSS is a fast-time modeling tool for airport surface operation simulation developed by NASA. During simulation runs, SOSS receives scheduling outputs generated from an external scheduler algorithm that would manage the traffic movement on the airport surface. ${ }^{5}$ The ultimate goal of developing an ICN model (or SOSS ICN model) is to establish the surface traffic management environment and capability to help test and validate new and promising operational concepts. Once congestion conditions and key operational constraints are identified, the simulation models including nodelink model, taxi-routes, runway operation rules, and simulation scenarios, which represent the congestion conditions and key operational constraints, can be developed. Then, strategies and potential solutions for efficient traffic management will be developed and evaluated using the fast-time simulation models. Higher fidelity and complex human-in-the-loop

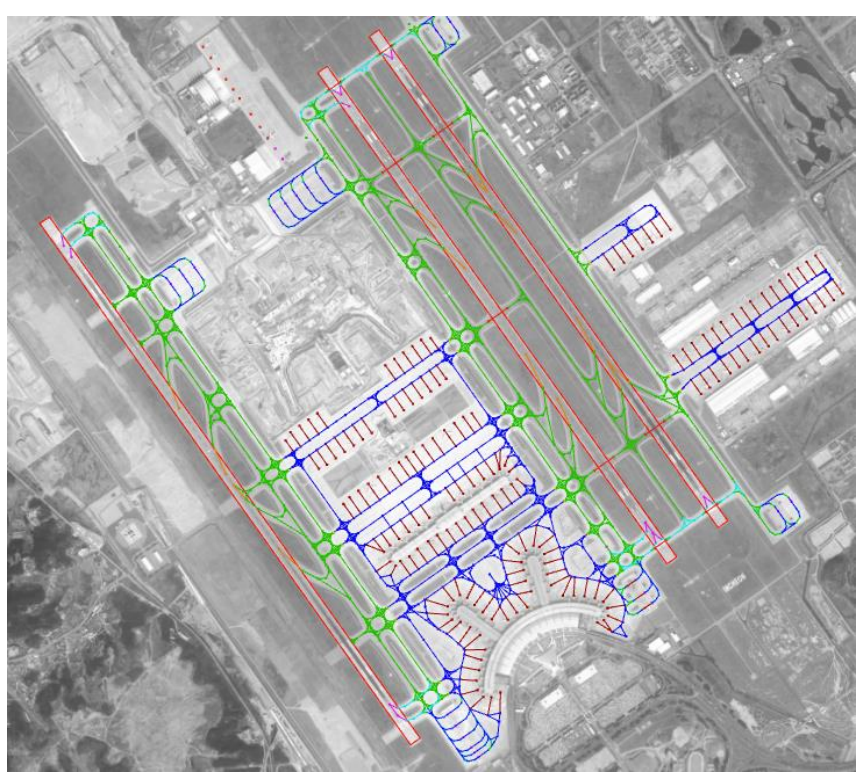

Figure 12. Visualization of ICN model node-link graph simulation studies can be conducted to further investigate the new operational concepts and validate the scheduling algorithm in a realistic environment. In NASA's surface management simulation environment, both the fast-time and real-time human-in-the-loop simulations use the common airport model that was validated against the current day operation data and conditions.

Figure 12 shows a snapshot of the node-link graph representing taxiways and runway in the SOSS model for ICN. Nodes, links, and taxi routes (not shown in the figure) were first created in accordance with the pushback guideline descriptions and the aircraft parking and moving chart of Aeronautical Information Publications (AIP). Then, these were modified using the actual aircraft movement paths identified from the ASDE ground tracks of the reconstructed flight data of April 2015. As a result, a total of 4,448 taxi routes were generated over the node-link model consisting of 1,533 nodes and 2,034 links. The frequency of usage for each taxi route was ranked, so that the most frequently used routes in the track data were set as default taxi routes during simulations.

The runway separation rules in the SOSS ICN model specify the relevant safety separation criteria required for runway operations. Tables 4-6 show the separation times in seconds for runway operations at ICN. The columns and rows represent the type of leading and following aircraft, respectively. In Standard Operation Procedure (SOP) of Incheon Control Tower ${ }^{15}$, separation rules are defined based on the weight class categories in ICAO Aircraft Type Designators $^{14}$, light, medium, and heavy. Super heavy aircraft (e.g., A380) has its own weight class in the runway separation rules for ICN operation ${ }^{15}$. It is assigned, however, as the heavy category in SOSS. The light, medium, and 
heavy categories in the ICAO Aircraft Type Designators are renamed as small, large, and heavy, respectively, in Table 4-6 to match the categories in SOSS. B757 has a dedicated category in SOSS since the weight class of B757 is suitable for the large type, but wake turbulence created by B757 is more severe than other large aircraft ${ }^{5}$. B757, however, is classified as a medium type according to ICAO Aircraft Type Designators, and the same separation times are given as the large type of aircraft considering real operations in ICN (see Table 4 and 5). The separation rules shown in Table 5 originate from the distance-based separation rule ${ }^{15}$, in which the required minimum distance of an arrival from the runway threshold is $4 \mathrm{~nm}$ for a departure before an arrival. Such distance-based separation requirements were converted into the time-based separation rules in Table 5, using the final approach speed of the representative aircraft model of each aircraft type. Since the distance between the two parallel runways, Runway $33 \mathrm{R} / 15 \mathrm{~L}$ and $33 \mathrm{~L} / 15 \mathrm{R}$, is only about $400 \mathrm{~m}$, the two runways should be operated with consideration for the arrivals and departures on each other, and the same separation rules are applied as with a single runway operation in mixed use. $^{15}$

Table 4. Separation matrix for consecutive departures on the same runway (seconds)

\begin{tabular}{|c|c|c|c|c|}
\hline & Small & Large & Heavy & B757 \\
\hline Small & 120 & 180 & 180 & 180 \\
\hline Large & 120 & 120 & 120 & 120 \\
\hline Heavy & 120 & 120 & 120 & 120 \\
\hline B757 & 120 & 120 & 120 & 120 \\
\hline
\end{tabular}

Table 5. Separation matrix for a departure before an arrival at coupled runways or on the same runway (seconds)

\begin{tabular}{|c|c|c|c|c|}
\hline & Small & Large & Heavy & B757 \\
\hline Small & 80 & 80 & 80 & 80 \\
\hline Large & 52 & 52 & 52 & 52 \\
\hline Heavy & 45 & 45 & 45 & 45 \\
\hline B757 & 52 & 52 & 52 & 52 \\
\hline
\end{tabular}

Table 6. Separation matrix for a departure after an arrival at coupled runways or on the same runway (seconds)

\begin{tabular}{|c|c|c|c|c|}
\hline & Small & Large & Heavy & B757 \\
\hline Small & 10 & 10 & 10 & 10 \\
\hline Large & 10 & 10 & 10 & 10 \\
\hline Heavy & 10 & 10 & 10 & 10 \\
\hline B757 & 10 & 10 & 10 & 10 \\
\hline
\end{tabular}

In ICN, a departure can start the takeoff roll right after the preceding arrival leaves the runway, which means the separation times for a departure after an arrival at coupled runways or on the same runway can be all zeros. However, the 10-second separation rule is applied, to account for reaction times in real operations (see Table 6).

\section{Simulation Model Validation}

Validity of the SOSS ICN model was investigated through a simulation model validation process. The validation is conducted by comparing the simulation results to the actual flight operation data using a set of selected performance metrics ${ }^{5}$. Figure 13 depicts the conceptual process of the SOSS ICN model validation, where 'Operation data' means the actual flight data, which is 'Reconstructed flight data' in Table 1, and also used for development of 'Traffic scenarios.' In this validation process, no external scheduling algorithm was incorporated. The purpose of this validation is to verify the usefulness of the developed SOSS ICN model for baseline simulation without scheduling algorithms, and therefore it is also useful to assess the improvement by the new scheduling algorithms which will be developed and incorporated in the simulation as a future study.

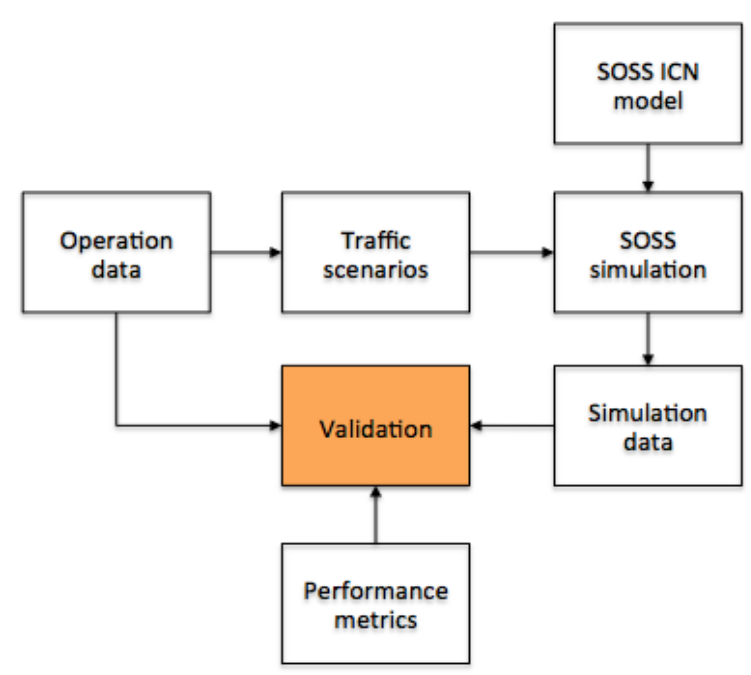

Figure 13. Conceptual process of the SOSS ICN model validation 


\section{A. Traffic Scenarios}

The traffic scenarios for the validation are derived from the actual flight data of April 2015. Four scenarios were developed as shown in Table 7. They represent the heavy departure traffic conditions on each departure runway. In other words the average departure rates per 15-minute time intervals shown in Table 7 match the saturated values in the departure throughput saturation curves shown in Fig. 11. In ICN, heavy departure traffic usually happens on Runway 33L/15R when the number of departure runways is changing from two to one. Such time periods are included in Cases No. 1 and 2.

Table 7. Selected time periods for the simulation scenarios and descriptions

\begin{tabular}{|c|c|c|c|c|c|c|}
\hline $\begin{array}{c}\text { Case } \\
\text { No. }\end{array}$ & Date & $\begin{array}{c}\text { Time Range } \\
\text { (Duration) }\end{array}$ & $\begin{array}{c}\text { Departure } \\
\text { Direction }\end{array}$ & Departure Runways & Situation Description & $\begin{array}{c}\text { Averaged Value } \\
\text { of the Departure } \\
\text { Rate (/15-minute) }\end{array}$ \\
\hline 1 & $30^{\text {th }}$ & $\begin{array}{c}20: 00-23: 00 \\
(3 \text { hours })\end{array}$ & North & $\begin{array}{c}33 \mathrm{~L}, 34 \rightarrow 33 \mathrm{~L} \\
\text { (changed at 21:00) }\end{array}$ & $\begin{array}{l}\text { Heavy departure traffic } \\
\text { on Runway 33L }\end{array}$ & $\begin{array}{c}6.25 \\
\text { on Runway 33L }\end{array}$ \\
\hline 2 & $12^{\text {th }}$ & $\begin{array}{c}14: 00-16: 30 \\
(2.5 \text { hours) }\end{array}$ & South & $\begin{array}{c}15 \mathrm{R}, 16 \rightarrow 15 \mathrm{R} \\
\text { (changed at 15:00) }\end{array}$ & $\begin{array}{l}\text { Heavy departure traffic } \\
\text { on Runway 15R }\end{array}$ & $\begin{array}{c}6.5 \\
\text { on Runway 15R }\end{array}$ \\
\hline 3 & $11^{\text {th }}$ & $\begin{array}{c}08: 30-10: 00 \\
(1.5 \text { hours })\end{array}$ & North & $33 \mathrm{~L}$ and 34 & $\begin{array}{l}\text { Heavy departure traffic } \\
\text { on Runway 34 }\end{array}$ & $\begin{array}{c}6.8 \\
\text { on Runway 34 }\end{array}$ \\
\hline 4 & $12^{\text {th }}$ & $\begin{array}{c}19: 00-21: 00 \\
(2 \text { hours })\end{array}$ & South & $15 \mathrm{R}$ and 16 & $\begin{array}{l}\text { Heavy departure traffic } \\
\text { on Runway 16 }\end{array}$ & $\begin{array}{c}5.5 \\
\text { on Runway 16 }\end{array}$ \\
\hline
\end{tabular}

The attributes of the actual flight data used to create the flight schedules in the scenarios include, but are not limited to, runway assignment, actual time of arrival (ATA), and actual time of departure (ATD). The ATA and ATD are considered as the wheels-on time and wheels-off time, respectively, and used as reference times to match the original schedules of the real flight data.

\section{B. Performance Metrics for Validation}

Three different groups of metrics were selected to compare the simulation results with real flight data, as shown in Table 8. The capacity utilization, represented by arrival and departure rates, indicates how effectively the operation utilizes the design capacities of an airport, and the simulation model should not impose any additional restriction to the capacity utilization. The metrics in traffic movement performance group measure the taxi performance and surface congestion conditions. The comparison of simulated and actual taxi performance will also facilitate the evaluation of the potential effectiveness of the scheduling algorithm's strategy aimed at improving operational performance. Assessment of the taxi route difference between the simulation and actual operation is useful for the validation of the taxi routes and can also provide supplementary information for taxi performance analysis.

Table 8. Selected performance metrics for SOSS ICN model validation

\begin{tabular}{|c|l|l|}
\hline Type & \multicolumn{1}{|c|}{ Metric } & \multicolumn{1}{c|}{ Description } \\
\hline $\begin{array}{c}\text { Capacity } \\
\text { Utilization }\end{array}$ & Arrival Throughput & Number of arrivals (wheels-on) in each 15-minute time interval \\
\cline { 2 - 3 } $\begin{array}{c}\text { Traffic } \\
\begin{array}{c}\text { Movement } \\
\text { Performance }\end{array}\end{array}$ & Departure Throughput & $\begin{array}{l}\text { Number of departures (wheels-off) in each 15-minute time } \\
\text { interval }\end{array}$ \\
\cline { 2 - 3 } & Taxi-in Time & $\begin{array}{l}\text { Number of departure flights taxiing-out, i.e., after gate off-block } \\
\text { and before wheels-off at a runway, in each 15-minute time } \\
\text { interval }\end{array}$ \\
\cline { 2 - 3 } $\begin{array}{c}\text { Model Spatial } \\
\text { Conformance }\end{array}$ & Taxi-out Time & Arrival taxi time from wheels-on to gate in-block \\
\hline
\end{tabular}

\section{Validation Results}

Figures 14 and 15 show the arrival throughput changes and cumulative arrivals, which were measured in consecutive 15-min time intervals, respectively. The differences at certain times represent one flight count, and were caused by several seconds difference between the arrival times of actual flight data and simulated results. Since the 
arrival landing times used in the scenarios are identical (i.e., extracted from the actual flight data), the throughput comparisons between the actual flight data and the SOSS simulated data must show good match in all scenarios.
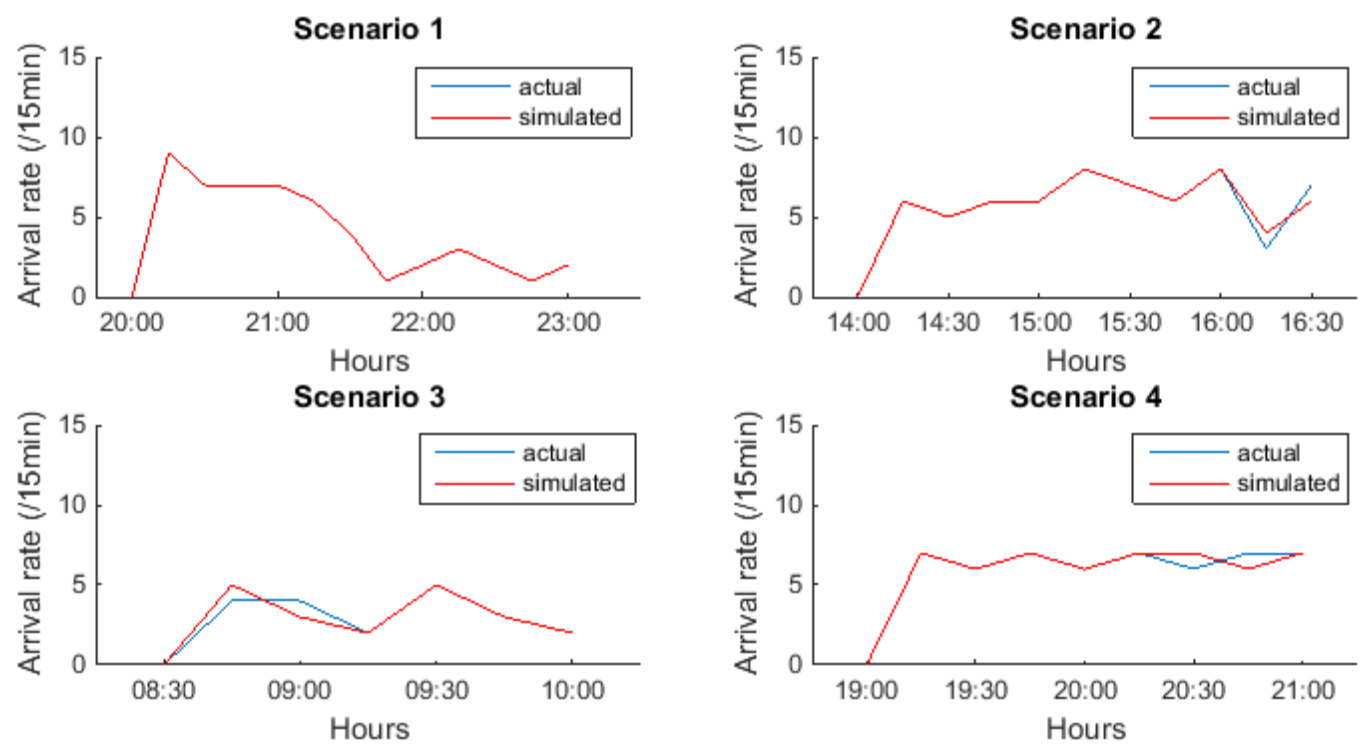

Figure 14. Arrival throughputs
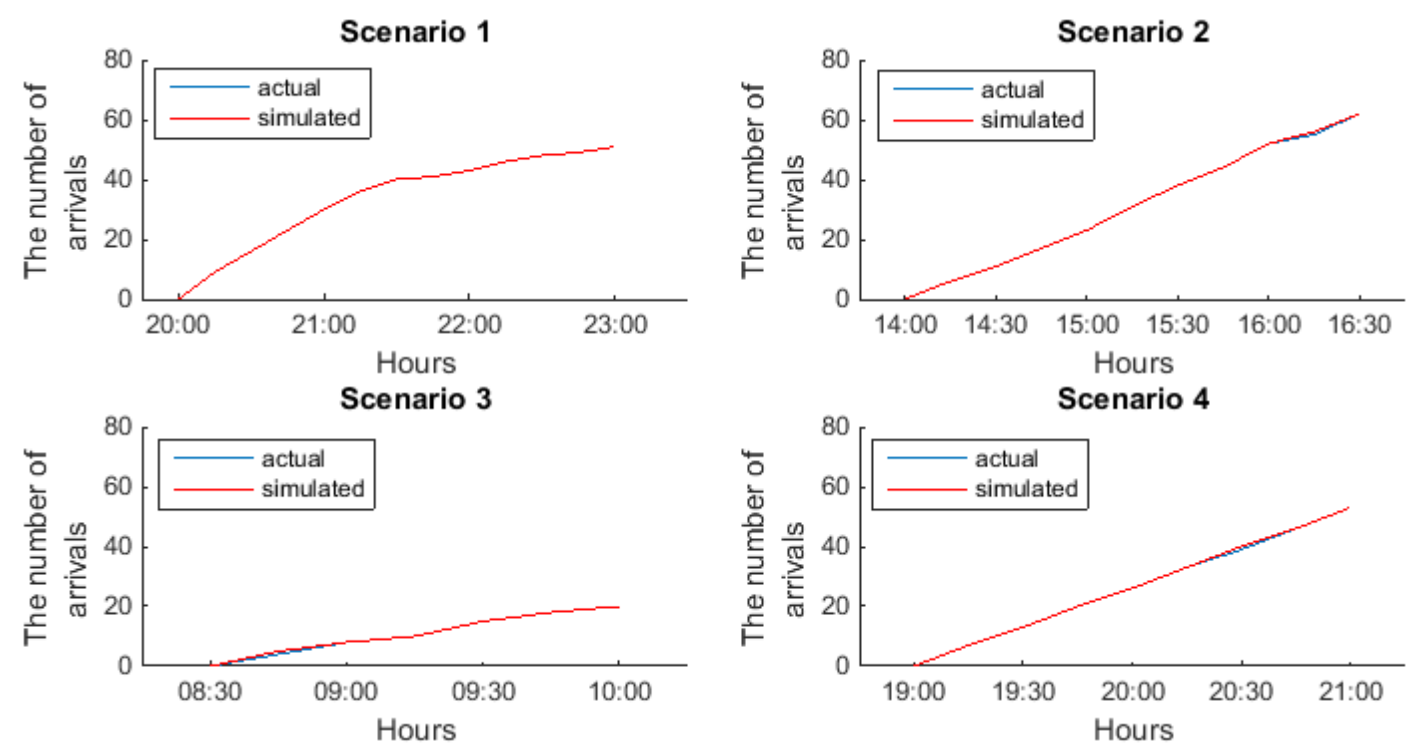

Figure 15. Cumulative arrivals

Figures 16 and 17 show the departure throughput comparisons. The plots show evident differences between simulation and actual operation. The primary cause lies in the combination of inaccurate wheels-off times based on ATDs and optimistic off-block time estimates in the simulation scenarios. ATD is automatically recorded when a departure track is initiated by the tracker in the Automated Radar Terminal System (ARTS). Wheels-off time is estimated based on the altitude attribute in the reconstructed flight data. These two are not always the same. The estimated wheels-off times are used to count the departure throughput for the actual operations. Secondly, the offblock times in the simulation scenarios are calculated backwards from the ATDs using the unimpeded taxi-out times, since the actual off-block times are unknown. Under a heavy traffic condition, this estimate could be too optimistic. Consequently, departure flights reach the runway 'late' in simulations. The biggest difference occurs in Scenario 1 between 20:00-20:30 with 25\% 'loss of departure throughput'. As described in Table 7, both Runway 33L and 34 are used for departures before 21:00, then Runway 34 closes at 21:00 as a regular runway operation in ICN. During the time period after 21:00 departure flights often encounter heavy traffic due to the closure of Runway 34/16. 
Moreover as denoted in Fig. 14, the high demand of arrivals on the Runway 33R generates crossing demand on Runway 33L. Such severe surface congestion conditions around Runway 33L/15R can be revealed in other metrics, such as departure queue size.
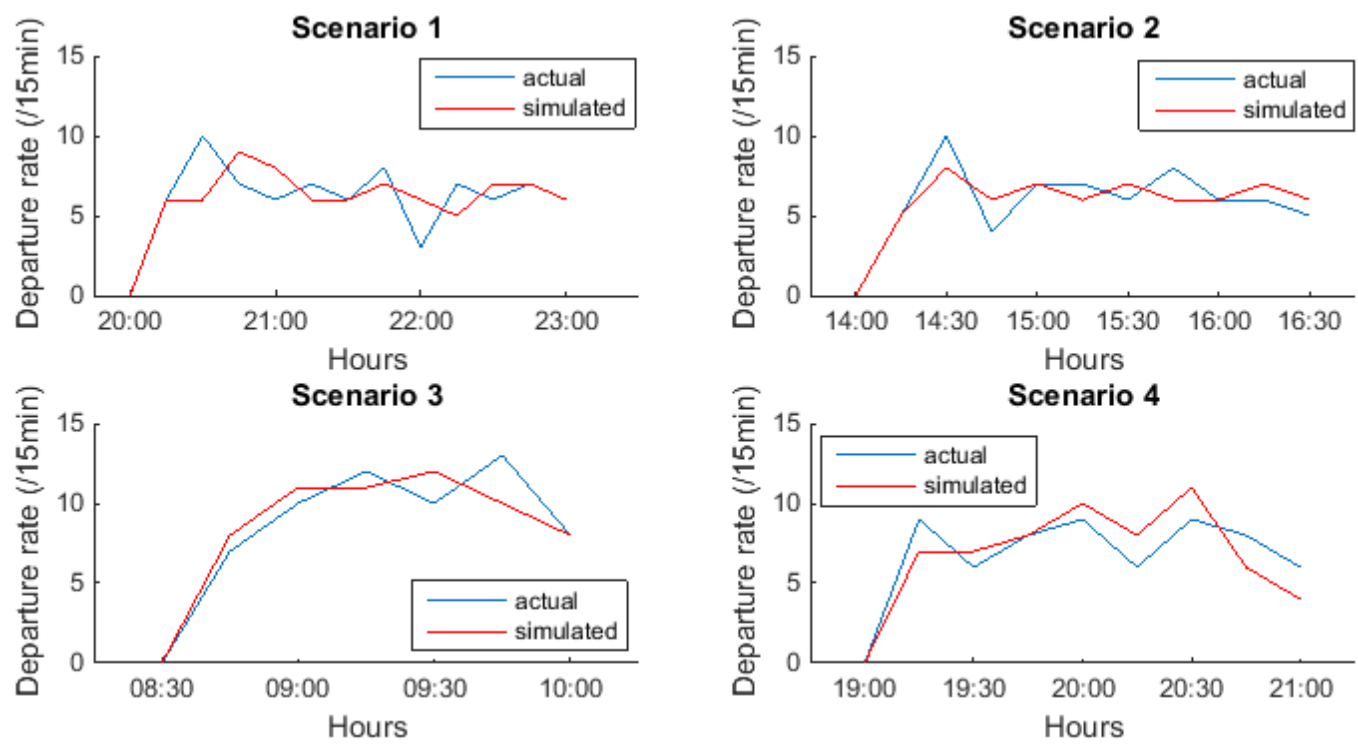

Figure 16. Departure throughputs
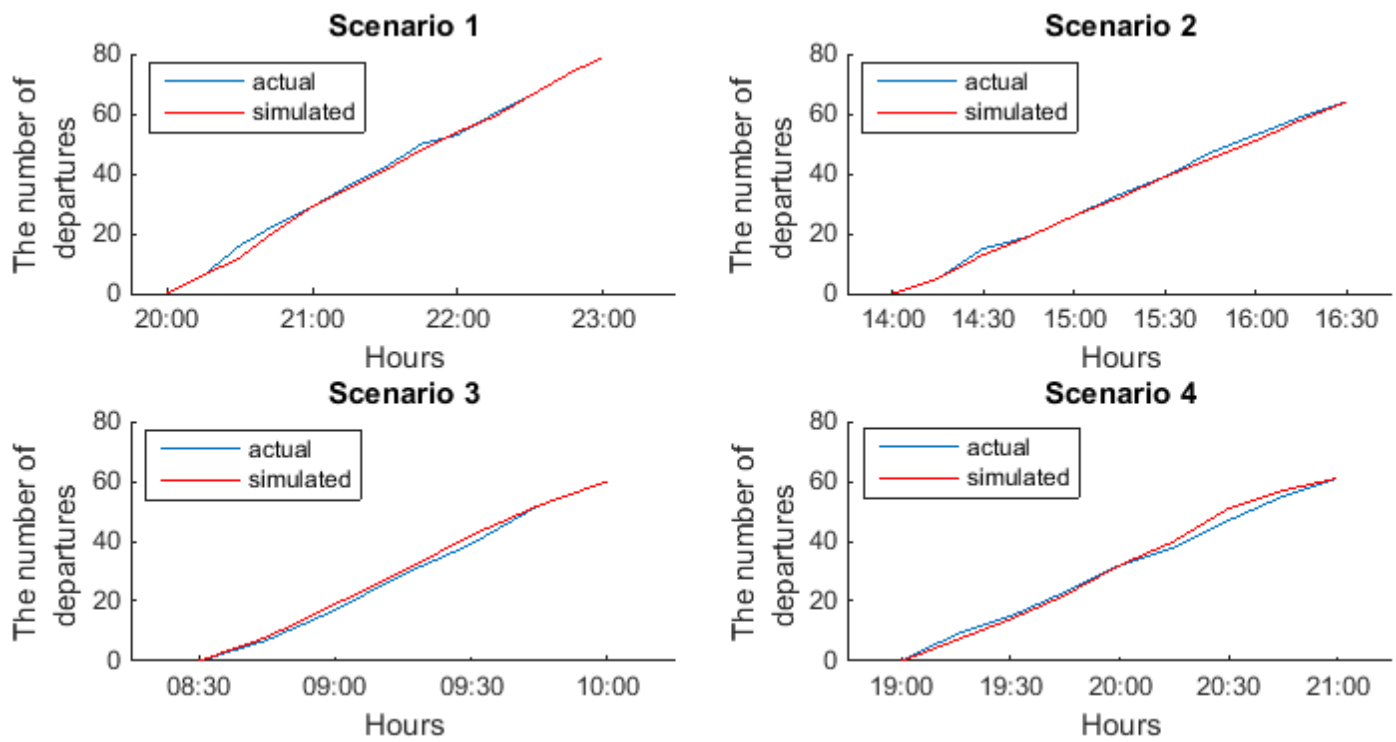

Figure 17. Cumulative departures

The departure queue sizes, plotted in Fig. 18, are defined as the number of departure flights taxiing-out on the surface, i.e., after off-block and before wheels-off at a runway. It is measured at a time instance with a 5-minute increment. Well matched results are shown in the comparisons, except for the delayed peak in Scenario 1 during 20:00-21:00, that is consistent with the departure throughput comparison shown in Figs. 16 and 17. 

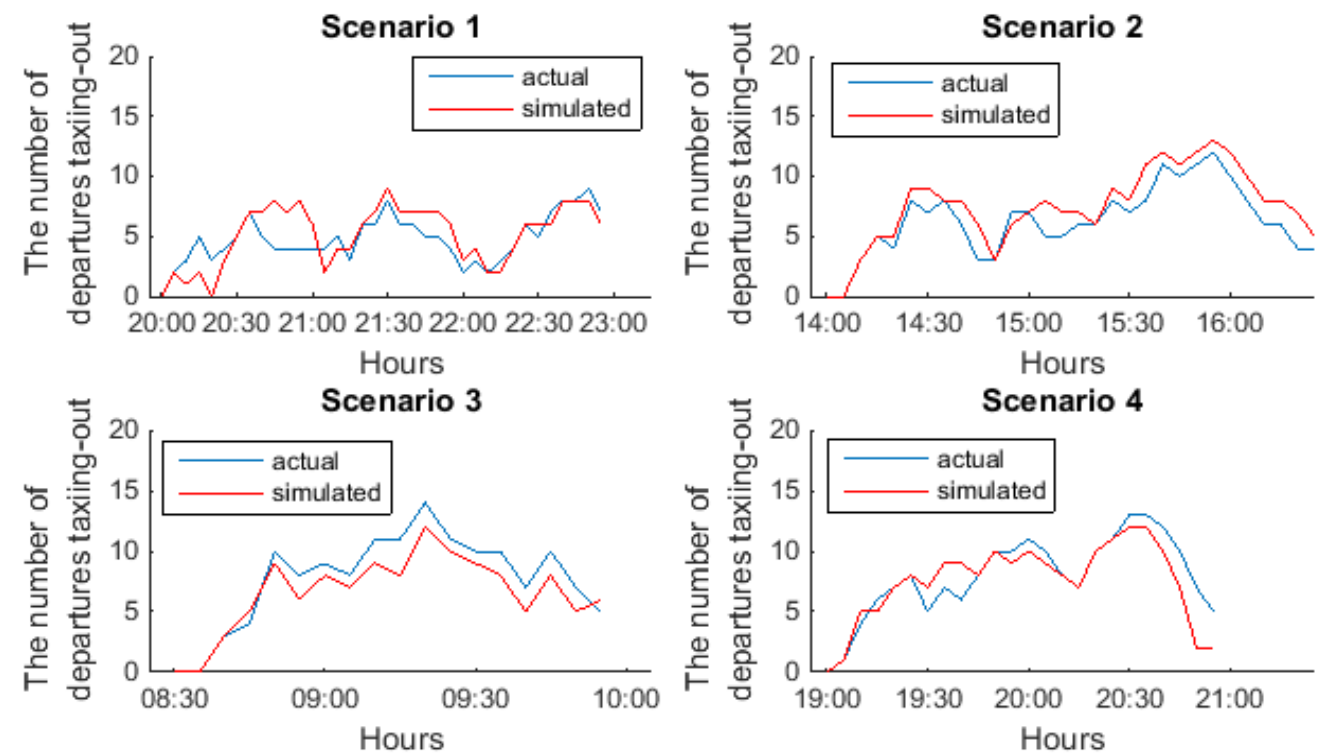

Figure 18. Departure queue sizes

Figure 19 shows the taxi-in and taxi-out time histograms. The top two graphs depict the overall taxi-in and taxiout time distributions, and the taxi time difference distributions are shown in the two graphs at the bottom. Many factors affect these distributions, such as taxi route, taxi speed, stops during taxiing, and data measurement errors. The standard deviations of taxi-in times are 2.99 minutes for the simulation and 2.65 minutes for the real operation. For taxi-out times, the standard deviations are 5.30 minutes for the simulation and 5.74 minutes for the real operation. Even though the mean value of the differences of the taxi-in times is 1.82 minutes, other distribution characteristics are well matched.
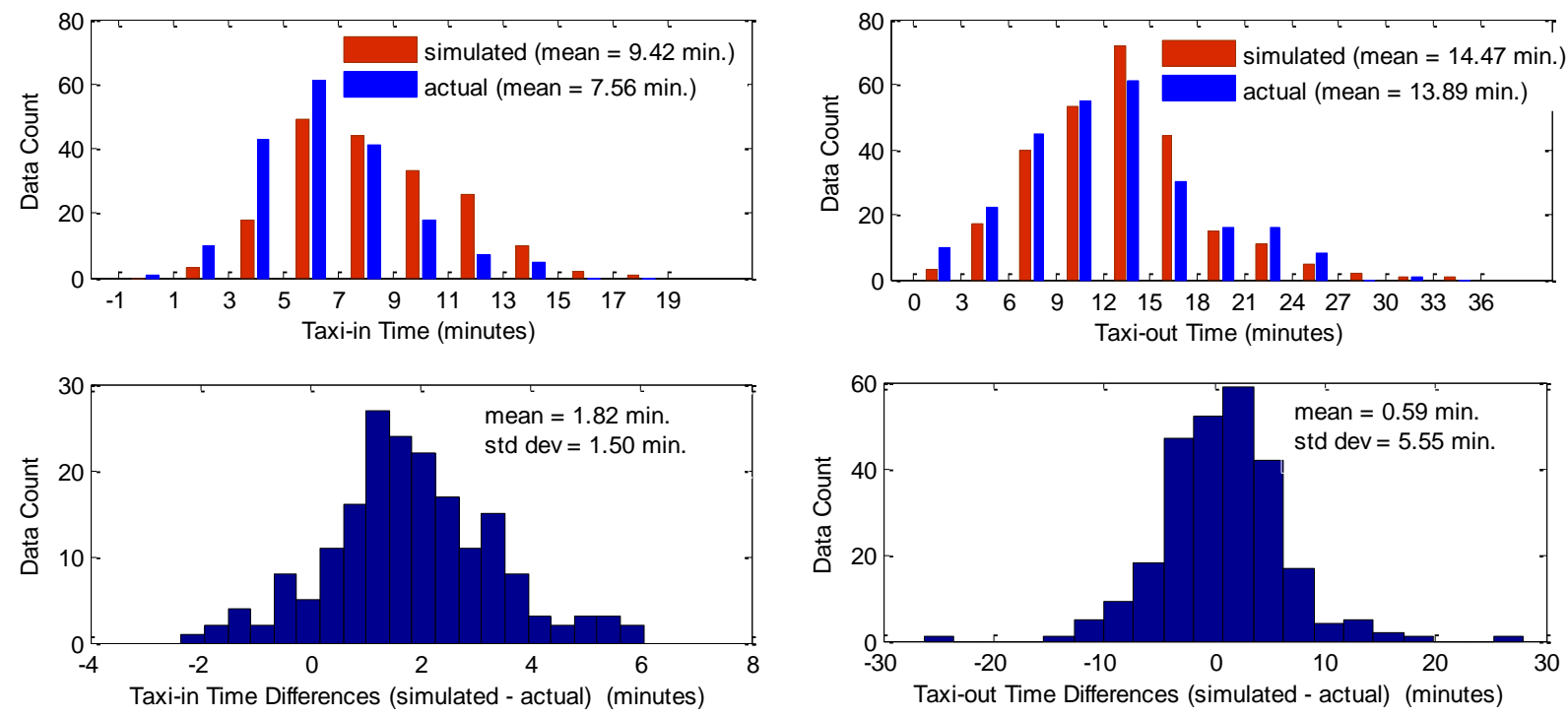

Figure 19. Histograms of taxi times

For the short taxi-in times of actual flight data (averaged 1.82 minutes difference from the simulated data), a possible explanation is the measurement errors, such as the shorter taxi-in trajectories in the ASDE ground tracks. The adjacent areas right beside of the terminal buildings are blocking areas of the ASDE radar due to the noise clusters, and therefore the tracks are not able to reach the in-block positions (as shown in Fig. 20). Note that in both operation and simulation the taxi-out times are much longer and more scattered with larger standard deviations, which implies much higher incident of stops and holdings during taxi-out than during taxi-in. Other factors 
particularly imposed to the departures, such as push-back holdings, stops or decelerations in departure queues, can make more significant impact on the taxi time differences than do the incomplete taxi trajectories in ASDE data.

The trajectory deviation comparisons are presented in Figs. 20 and 21. The trajectories in yellow color are rendered on top of the airport node-link model. On the left is from ASDE ground tracks and right from the simulation output. Due to the same reason as the shortened taxi-in trajectories of ASDE track data, the taxi-out trajectories of ASDE tracks do not start from the gate positions. Some deviations of the taxi routes are recognizable, and the conformance rates of the taxi routes are $83.15 \%$ for arrivals and $73.70 \%$ for departures. The conformance rates of the taxi routes are measured as the ratio of the flights of which taxi routes coincide in actual flight data and simulation. The coincidence in taxi routes means identical routes in both ramp and movement areas, from a gate to a departure runway for taxi-out, and from a runway to a gate for taxi-in. In simulation using SOSS without external scheduling algorithms, default taxi-in and taxi-out routes from/to each runway to/from each gate are utilized. Even though the default taxi routes were selected as the most frequently used routes in the ASDE ground tracks in development of the SOSS ICN model as described in Section V, taxi routes can change in real operations, depending on traffic congestions and surface conditions. It is also known that, in ICN, the controllers often change the taxi route for smooth movement of a flight avoiding route conflicts with other flights, especially in Main Ramp. Based on the taxi-routes identified using the ASDE ground tracks in Section V, heuristic strategies for tactical assignment or re-routing of taxi-routes can be incorporated in the scheduling algorithm, which will be developed and evaluated using the same SOSS ICN model in the future study.
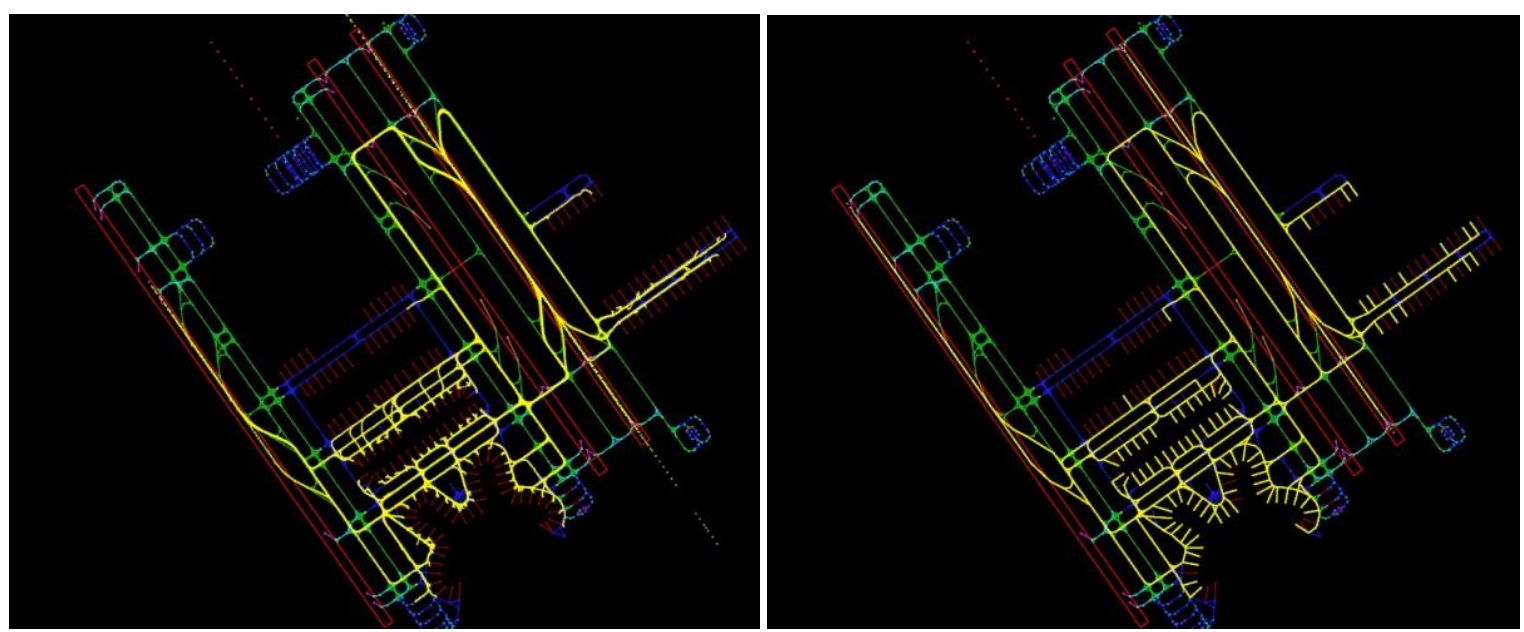

Figure 20. Arrival Tracks Comparison (left: ASDE ground tracks, right: simulated tracks)
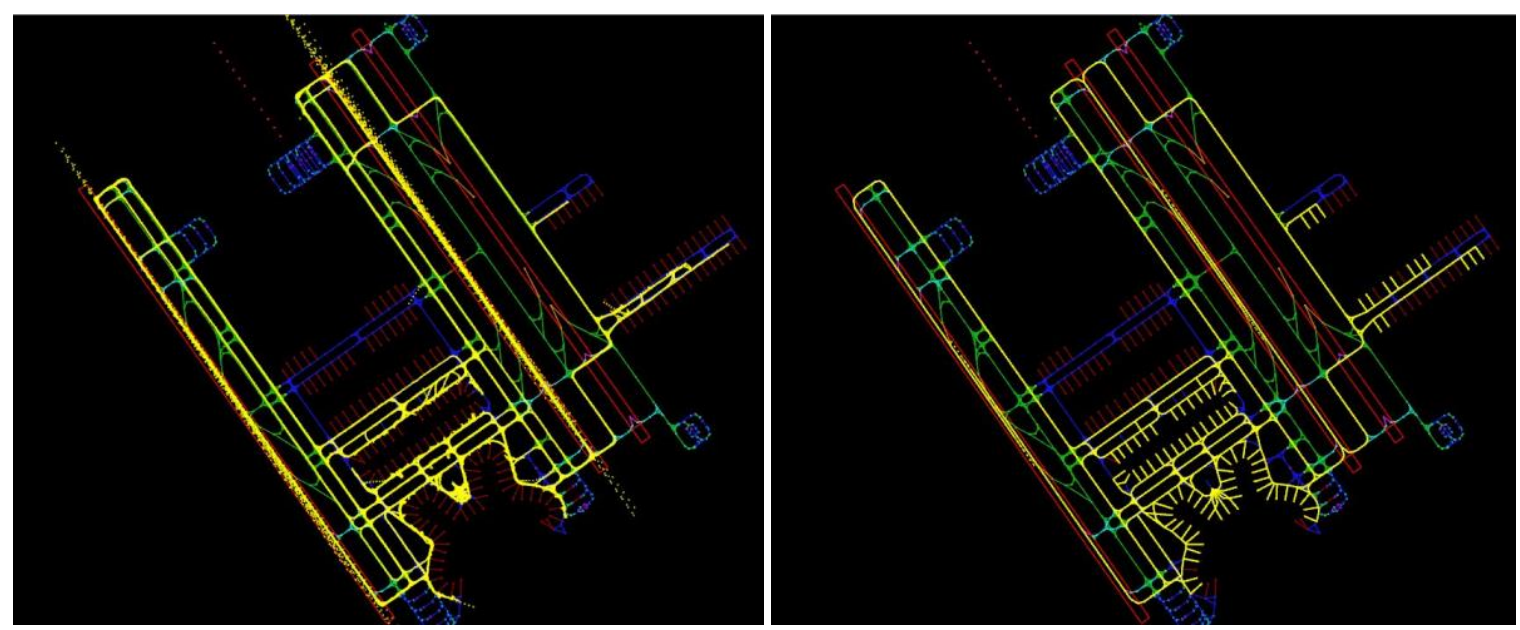

Figure 21. Departure Tracks Comparison (left: ASDE ground tracks, right: simulated tracks) 


\section{Conclusion}

As initial research for surface and departure management of ICN, data analysis using actual flight data, fast-time simulation model development, and model validation were successfully conducted. In the data analysis, surface tracks from ASDE surveillance system and operational information from FIMS and FOIS in April 2015 were used. Surface traffic heat maps were created to identify the congestion and choke points at the airport surface. Runway configuration/assignment strategies, runway departure throughput, and demand characteristics were investigated.

The surface traffic heat map analysis can be regarded as a quantitative approach to identifying the locations and intensities of the surface choke points. This approach will be useful to estimate and measure the improvement in surface traffic congestions when developing and testing the scheduling schemes or algorithms. Characteristics of the holding or stops of aircraft during taxiing, existence of the departure queues, which can be valuable considerations in applying surface scheduling algorithms, were also identified based on the heat map analysis.

According to the flight demand characteristics of ICN which were observed through the runway configuration and assignment strategy analysis, the demand of WS-bound flights is much higher than the demand of ES-bound flights, and the peak hours of overall departure demand were caused mainly by WS-bound flights. The usage of Runway 34/16 is dependent on the traffic demand of the WS-bound flights, and it is used for departures during high demand period of WS-bound flights. The flight directions play a major role in runway assignments for departures, whereas aircraft wake turbulence categories do not.

The analysis results of runway departure throughputs can be useful to indicate surface traffic congestion levels, which have strong influence on the taxi-out times. The saturated values of the throughput is also useful as reference values for controlling the number of taxiing-out departures in the movement areas in development of a surface traffic management scheme.

Base on the actual flight data of April 2015, a simulation model consisting of a node-link model and runway separation rules of ICN, and the simulation scenarios of heavy traffic situations in four different runway configurations were developed for fast-time simulation using SOSS. The developed simulation model was validated by comparing the simulation results with the actual flight data, using a set of performance metrics. The validation results show that the developed simulation model is a good approximation to represent ICN operations and is useful for future study of ICN surface operations and development of new scheduling concepts and algorithms.

\section{Acknowledgments}

This work was performed under the ATM research collaboration between KAIA/KARI and NASA. KARI is greatly indebted to Ministry of Land, Infrastructure, and Transport (MOLIT) of Korea, KAIA, and Incheon International Airport Corporation (IIAC) for their funding and support.

\section{References}

${ }^{1}$ Levy, B., Carpenter, M., DeHart, S., Nolan, T., Boudreau, R., and Watkins, Q., “Airport Surface Surveillance Data Improves Pavements Management Efficiency and Cost Effectiveness," the 2014 FAA Worldwide Airport Technology Transfer Conference, Calloway, NJ, Aug. 2014. URL: http://www.airtech.tc.faa.gov/ATT2014/Papers/P10033\%20-\%20Levy\%20et\%20al.pdf [cited 25 Oct. 2015].

${ }^{2}$ Gupta, G., Malik, W., Tobias, L., Jung, Y., Hoang, T., and Hayashi, M., "Performance Evaluation of Individual Aircraft Based Advisory Concept for Surface Management," the Tenth USA/Europe Air Traffic Management Research and Development Seminar, Chicago, IL, Jun. 2013.

${ }^{3}$ Hayashi, M., Hoang, T., Jung, Y. C., Malik, W., Lee, H., and Dulchinos, V. L., "Evaluation of Pushback Decision-Support Tool Concept for Charlotte Douglas International Airport Ramp Operations," the Eleventh USA/Europe Air Traffic Management Research and Development Seminar, Lisbon, Portugal, Jun. 2015.

${ }^{4}$ Khadilkar, H., and Balakrishnan, H., "Analysis of Airport Performance using Surface Surveillance Data: A Case Study of BOS," the 11 $11^{\text {th }}$ AIAA Aviation Technology, Integration, and Operations (ATIO) Conference, Virginia Beach, VA, Sep. 2011.

${ }^{5}$ Windhorst, R. D., Montoya, J. V., Zhu, Z., Gridnev, S., Griffin, K. J., Saraf, A., and Stroiney, S., "Validation of Simulations of Airport Surface Traffic with the Surface Operations Simulator and Scheduler," the $13^{\text {th }}$ AIAA Aviation Technology, Integration, and Operations (ATIO) Conference, Los Angeles, CA, Aug. 2013.

${ }^{6}$ EUROCONTROL, “The Manual: Airport CDM Implementation,” v. 4, Brussels, Belgium, 2012.

${ }^{7}$ The Federal Aviation Administration, "U.S. airport surface Collaborative Decision Making (CDM) concept of operations (ConOps) in the near-term (draft)," Air Traffic Organization Surface Operations Directorate, Washington, DC, Jul. 2013.

${ }^{8}$ Simaiakis, I., Khadilkar, H., Balakrishnan, H., Reynolds, H. G., Hansman, R. J., Reilly, B., and Urlass, S., "Demonstration of Reduced Airport Congestion through Pushback Rate Control," the Ninth USA/Europe Air Traffic Management Research and Development Seminars, Berlin, Germany, Jun. 2011. 
${ }^{9}$ Gupta, G., Malik, W., and Jung, Y., "An Integrated Collaborative Decision Making and Tactical Advisory Concept for Airport Surface Operations Management," 12th AIAA Aviation Technology, Integration, and Operations (ATIO), Indianapolis, IN, Sep. 2012.

${ }^{10}$ Brinton, C., Provan, C., Lent, S., Prevost, T., and Passmore, S., "Collaborative Departure Queue Management: an Example of Airport Collaborative Decision Making in the United States," the Ninth USA/Europe Air Traffic Management Research and Development Seminars, Berlin, Germany, Jun. 2011.

${ }^{11}$ Aponso, B., Coppenbarger, R., Jung, Y., O’Connor, N., Lohr, G., Quon, L., and Engelland, S., "Identifying Key Issues and Potential Solutions for Integrated Arrival, Departure, Surface Operations by Surveying Stakeholder Preferences," AIAA 20152590, $15^{\text {th }}$ AIAA Aviation Technology, Integration, and Operations (ATIO) Conference, Dallas, Texas, Jun. 22-26, 2015.

${ }^{12}$ International Civil Aviation Organization, "Manual on Collaborative Air Traffic Flow Management," $2^{\text {nd }}$ Edition, Doc 9971/AN485, Montreal, Quebec, Canada, 2014.

${ }^{13}$ Republic of Korea, "Low Visibility Procedures Upgrade - Implementing Practical Solutions to Large-sized Airports," ANConf/12-IP/42, ICAO 12 th Air Navigation Conference, Montreal, Quebec, Canada, Nov. 2012.

14 International Civil Aviation Organization, "DOC 8643 - Aircraft Type Designators," Mar. 2016, URL: http://cfapp.icao.int/Doc8643/reports/Part2-By\%20Type\%20Designator(Decode).pdf [cited 14 Apr. 2016].

${ }^{15}$ Seoul Regional Aviation Administration, "Incheon Control Tower Standard Operating Procedures," Republic of Korea, Jun. 2015.

${ }^{16}$ Korea Civil Aviation Development Association, Pocket Aviation Status 2015, Republic of Korea, Jun. 2015. 